\title{
Clinical use and limitation of haemoglobin A1c examination
}

\section{ABSTRACT}

Haemoglobin A1c (HbA1c/A1C) is a part of haemoglobin $(\mathrm{Hb})$ that binds to glucose through non-enzymatic reactions. In general, $\mathrm{HbA} 1 \mathrm{c}$ is used as a parameter for diagnosis, target therapy and monitoring or prediction of long-term complications of diabetes mellitus (DM) outcome. However, HbA1c can also be used to predict the incidence of DM and vascular outcomes in those without DM. HbA1c above $6.5 \%$ is used as the limit for diagnosing DM, and in general, HbA1c $<7.0 \%$ is used as the target limit of therapy in adult DM patients. As a parameter for the diagnosis of DM and long-term monitoring, $\mathrm{HbA} 1 \mathrm{c}$ has limitations and advantages over blood glucose testing, because HbA1c is strongly influenced by several conditions that affect the life span of erythrocytes where $\mathrm{Hb}$ will remain throughout the life of the cell. Likewise, HbA1c cannot assess the variability of blood glucose levels short-termly and cannot determine the presence of hypoglycaemia. With all its limitations, now HbA1c has been established as a parameter to diagnose DM and the most reliable parameter in predicting the incidence of chronic complications from DM. (Clin Diabetol 2021; 10; 3: 299-307)

Key words: HbA1c, predictor, diagnostic, prognostic, diabetes

\footnotetext{
Address for correspondence:

Ketut Suastika

Division of Endocrinology \& Metabolism

Department of Internal Medicine, Faculty

of Medicine Udayana University, Sanglah Hospital

Jl. Diponegoro, Denpasar, Bali, Indonesia 80113.

e-mail: ksuas@unud.ac.id

Clinical Diabetology 2021, 10; 3: 299-3075

DOI: 10.5603/DK.a2021.0045
}

Received: 30.09 .2020

Accepted: 28.12 .2020

\section{Introduction}

In normal adult erythrocytes, haemoglobin $(\mathrm{Hb})$ consists of haemoglobin $\mathrm{A}(\mathrm{HbA}[\alpha 2 \beta 2])$ in about $97 \%$ of these protein molecules, haemoglobin $\mathrm{A} 2(\mathrm{HbA} 2$ $[\alpha 2 \delta 2])$ is about $2 \%$, and haemoglobin $\mathrm{F}$ or foetal haemoglobin ( $\mathrm{HbF}[\alpha 2 \gamma 2])$ is about 1\% [1]. Chromatographically, $\mathrm{HbA}$ consists of $\mathrm{HbAO}$ (92-94\%) and HbA1 (6-8\%) where the beta chain is an additional glucose group. HbA1 consists of 3 different glycations, wherein $\mathrm{HbA} 1 \mathrm{c}$ is usually measured by isoelectric focusing or electrophoresis [2]. Non-enzymatic $\mathrm{Hb}$ glycation is a tiered process in which glucose and other substances bind spontaneously. This reaction first forms an unstable Schiff base complex which dissociates in the absence of glucose or slowly forms a more stable Amadori product in the presence of glucose [3]. Glycated haemoglobin, known as haemoglobin $\mathrm{A} 1 \mathrm{c}$ ( $\mathrm{HbA} 1 \mathrm{c}$ or $\mathrm{A} 1 \mathrm{C})$, is a form of $\mathrm{Hb}$ that is examined primarily with regard to the mean plasma glucose level over a long period. $\mathrm{HbA} 1 \mathrm{c}$ is formed from the non-enzymatic glycation pathway of $\mathrm{Hb}$ exposed to plasma glucose. $\mathrm{HbA} 1 \mathrm{c}$ is $\mathrm{Hb}$ with beta- $\mathrm{N}-1$ deoxy fructosil component; undergoes irreversible glycation of one or two valine $\mathrm{N}$-terminals of the beta chain. Once the $\mathrm{Hb}$ molecule undergoes glycation, it remains in the red blood cell for the rest of its life (120 days) [2, 4]. The non-enzymatic reaction between haemoglobin and glucose is shown in Figure 1 [4].

There are two main analytical concepts in the HbA1c examination, namely: (1) based on the separation of the $\mathrm{Hb}$ fraction and (2) based on chemical reactions. Although the two methods are different, the examination has been standardized according to the Reference Measurement Procedure (RMP) of the International Federation of Clinical Chemistry (IFCC). The $\mathrm{HbA} 1 \mathrm{c}$ value from the IFCC-RPM has been harmonized with existing standards, namely from the National Glycohemoglobin Standardization Program (NGSP). NGSP 


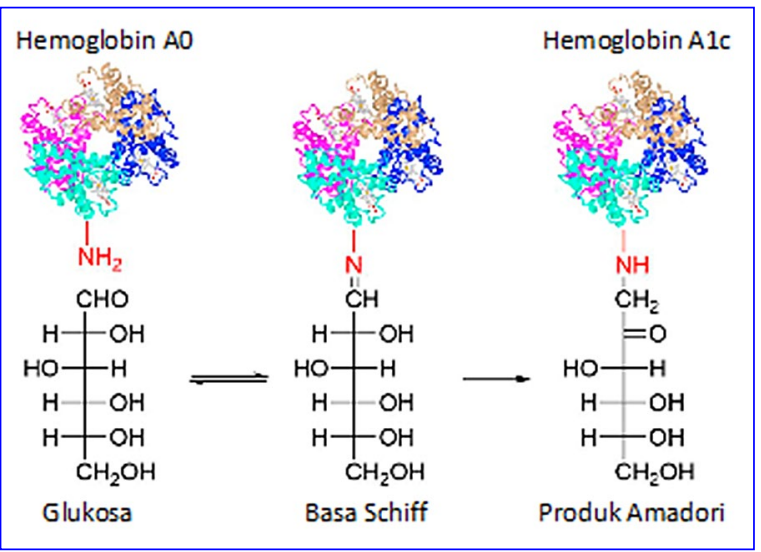

Figure 1. Steps of glycated haemoglobin (HbA1c) formation. Adapted from [4]

has been established in 1996 for the measurement of $\mathrm{HbA1c}$ and has been used in clinical studies such as DCCT and UKPDS. The master conversion equation from IFCC units to NGSP units is (NGSP\% $=0.0915 \times$ IFCC $\mathrm{mmoL} / \mathrm{mol}+2.15$ ) and vice versa (IFCC $\mathrm{mmoL} / \mathrm{mol}=$ 10.93 NGSP\% -23.5) [5-7]. From the above formula, an equivalent can be made between units \% (NGSP) and $\mathrm{mmoL} / \mathrm{mol}$ (IFCC) for example as follows: $4-6 \%=$ $20-42 \mathrm{mmoL} / \mathrm{mol} ; 7 \%=53 \mathrm{mmoL} / \mathrm{mol}$; and $8 \%=64$ $\mathrm{mmoL} / \mathrm{mol}$ [6].

The purpose of this literature review is to describe the role of $\mathrm{HbA} 1 \mathrm{c}$ as a parameter to predict the incidence of diabetes mellitus (DM) and cardiovascular disease (CVD) in normal populations, as a diagnostic parameter of diabetes and predict chronic complications of diabetes, as well as the limitations of the use of $\mathrm{HbA} 1 \mathrm{c}$ in clinical practice.

\section{HbA1c as a predictor for diabetes and vascular diseases in the non-diabetic population}

Bonora et al. [8] conducted a study on whether high normal $\mathrm{HbA} 1 \mathrm{c}$ levels could predict the incidence of type 2 diabetes (T2DM). This study was conducted on 919 Caucasian subjects, aged 40-79 years and recorded as having new T2DM after being followed for 15 years. The results were $\mathrm{HbA} 1 \mathrm{c}<5 \%, 5-5.49 \%$ (as reference), 5.50-5.99\%, and 6-6.49\%, in the baseline data after adjusting for sex and age, had hazard ratios (HR) for T2DM of each. 1.11, 1.00, 3.79, and 12.50 . It was concluded that $\mathrm{HbA} 1 \mathrm{c}$ is an independent risk factor for T2DM.

One systematic review study by Zang et al. (2010) investigated the role of early $\mathrm{HbA} 1 \mathrm{c}$ on the incidence of DM. From 16 studies, it was found that the annual incidence of DM ranged from $0.1 \%$ at $\mathrm{HbA} 1 \mathrm{c}<5 \%$ to
$54.1 \%$ at $\mathrm{HbA} 1 \mathrm{c}>6.1 \%$. From 7 studies, the incidence of DM based on the HbA1c category was found: (1) the risk of DM incidence increased gradually in the $\mathrm{HbA} 1 \mathrm{c} 5.0-6.5 \%$ range; (2) The $\mathrm{HbA} 1 \mathrm{c}$ range between 6.0-6.5\% was associated with a high incidence of DM, 25-50\% over 5 years; (3) HbA1c between $5.5-6.0 \%$ was associated with a moderate increase in relative risk of DM, 9-25\% incidence over 5 years; and (4) $\mathrm{HbA1c}$ between $5.0-5.5 \%$ was associated with an increased incidence relative to those with $\mathrm{HbA} 1 \mathrm{c}<5.0 \%$, but an absolute incidence of below $9 \%$ over 5 years. From this study, it was concluded that an $\mathrm{HbA} 1 \mathrm{c}$ between 5.5-6.5\% was associated with an increased risk of developing DM [9].

One study was conducted to evaluate the association between glycaemic variability and vascular incidence in mid-adulthood non-DM. From 10020 data Ansung-Ansan cohort, Korean Genome, and Epidemiology Study (KoGES), 6462 non-DM adults aged $<65$ years were analysed. The mean and coefficient of variation (CV) recorded twice a year from $\mathrm{HbA} 1 \mathrm{c}$, fasting blood glucose (FBG) and blood glucose after meals (PGB) were divided into 3 groups based on the measurement of each CV tertile, and the first tertile was used as control/reference. The main outcomes are macrovascular composites (coronary artery disease, myocardial infarction, congestive heart failure or stroke) and microvascular events (creatinine clearance $<60$ $\mathrm{mL} / \mathrm{min} / 1.73 \mathrm{~m}^{2}$ ). Subjects were followed for 9.9 years. High HbA1c-tertile CV (OR 1.30; 1.01-1.66) is a risk factor for microvascular events. In contrast, high FBG-CV (OR 2.32; 1.30-4.12) and PBG-CV (OR 1.85; 1.05-3.26) are risk factors for macrovascular events. In this 10-year cohort study, higher HbA1c-CV tertile was associated with the incidence of macro-and microvascular composites and free risk factors in mid-adult non-DM. In addition, higher levels of FBG-CV and PBG-CV are risk factors for macrovascular events [10].

Another study supports the above findings, that HbA1c levels are a risk factor for PKV outcome and death in both those with or without diabetes. The systematic review study and meta-analysis of CaveroRedondo et al. [11] found that for those without DM (reference $\mathrm{HbA1}$ c 5.0-6.0\%), the $\mathrm{HbA} 1 \mathrm{c}$ range between $5.0-6.0 \%$ was the best related to outcome. Above $6 \%$ led to an increase in CVD mortality with an HR of 1.74 (1.38-2.20). Meanwhile, HbA1c $<5.0 \%$ more causes death of all causes. Similar to those with DM (reference HbA1c 6.0-7.0\%), the respective HR for CVD was 1.69 (1.09-2.66) for $\mathrm{HbA} 1 \mathrm{c}>9.0 \%$ and $\mathrm{HbA} 1 \mathrm{c}<6.0 \%$ for all-cause death with HR 1.57 (1.14-2.17). The systematic review and meta-analysis of Mitsios et al. [12] showed a similar outcome for stroke. In this study, it 
was found that each $1 \%$ increase in $\mathrm{HbA} 1 \mathrm{c}$ increased the incidence of stroke and first-time ischaemic stroke by $1.12(0.91-1.39)$ and $1.49(1.32-1.69)$ for the nonDM cohort and respectively $1.17(1.09-1.25)$ and 1.24 (1.11-1.39) for the DM cohort. It was concluded by the investigators that increased $\mathrm{HbA} 1 \mathrm{c}$ was associated with an increased risk of first-time stroke in the DM cohort and ischaemic stroke in the non-DM cohort. These researchers suggest that more intensive $\mathrm{HbA} 1 \mathrm{c}$ reduction is necessary if it is to prevent the risk of ischaemic stroke.

Another interesting study is looking at the association of $\mathrm{HbA1}$ c variability with major cardiovascular events and all-cause mortality in a population without a history of DM and CVD, and with three annual $\mathrm{HbA} 1 \mathrm{c}$ measurements within the normal range $(<6.5 \%$ [48 $\mathrm{mmol} / \mathrm{mol}]$ ). Of the total 6756 subjects, the median followed up time was 6.3 years, 996 had major adverse cardiovascular events (MACE), 856 died, and 1267 developed T2DM. In this study, it was found that there was a significant relationship between $\mathrm{HbA} 1 \mathrm{c}$ variability and the incidence of MACE (HR 1.09 [1.03-1.15]) and all-cause mortality (HR 1.13 [1.07-1.20]), whereas no association was found with the incidence of DM [13].

\section{HbA1c for diagnosis of diabetes}

Diagnosis of DM is usually made based on laboratory tests, namely examination of FBG levels, 2 hours after a glucose load of 75 grams (2hPBG), random blood glucose, or $\mathrm{HbA} 1 \mathrm{c}$ examination. Based on $\mathrm{HbA} 1 \mathrm{c}$ examination, the diagnosis of DM was confirmed if an $\mathrm{HbA} 1 \mathrm{c}$ level of $\geq 6.5 \%$ was found. Called normal is if $\mathrm{HbA} 1 \mathrm{C}<5.7 \%$, and between $5.7-6.4 \%$ is called prediabetes $[14,15]$. The diagnosis criteria for DM based on HbA1c according to the NGSP unit (DCCT) and IFCC can be seen in Table 1 [16]. The use of HbA1c as a diagnostic criterion for DM cannot be applied in
Table 1. Diagnosis criteria of diabetes and other dysglycaemia by $\mathrm{HbA} 1 \mathrm{c}$

\begin{tabular}{lcc}
\hline & $\begin{array}{c}\text { DCCT (NGSP)- } \\
\text {-HbA1c (\%) }\end{array}$ & $\begin{array}{c}\text { IFCC-HbA1c } \\
\text { (mmoL/mol) }\end{array}$ \\
\hline Diabetes mellitus & $\geq 6.5$ & $\geq 48$ \\
Prediabetes & $5.7-6.4$ & $39-47$ \\
Normal & $\leq 5.6$ & $\leq 38$ \\
\hline
\end{tabular}

Adapted from [16]

the following situations: (1) conditions of red blood cell turnover, such as anaemia due to haemolysis, spherocytosis or iron deficiency (e.g. in pregnancy); (2) hemoglobinopathy, such as $\mathrm{HbS}, \mathrm{HbC}, \mathrm{HbF}, \mathrm{HbE}$, in sickle cell trait, requires special $\mathrm{HbA} 1 \mathrm{c}$ examination; (3) fast onset DM, such as T1DM and some T2DM, where $\mathrm{HbA} 1 \mathrm{c}$ is still within normal limits while there is severe hyperglycaemia; (4) HbA1c is considered inaccurate enough for diagnosis for patients who underwent examination some time ago. For those where $\mathrm{HbA} 1 \mathrm{c}$ is of doubt used to diagnose DM, it is better to use blood glucose testing [16]. The advantages and disadvantages of using blood glucose and $\mathrm{HbA} 1 \mathrm{c}$ tests to diagnose DM can be seen in Table 2 .

\section{HbA1c as the target of therapy and marker for vascular complication}

In general, in adult diabetic patients, the desired glycaemic target is $\mathrm{HbA} 1 \mathrm{c}<7 \%$, in addition to preprandial blood glucose between $80-130 \mathrm{mg} / \mathrm{dl}$ and peak blood glucose (1-2 hours after meals) is <180 $\mathrm{mg} / \mathrm{dl}$. The therapeutic goals may be tighter or looser depending on the patient's circumstances $[14,15]$. According to Davies et al. [16], to predict the incidence of microvascular complications, HbA1c levels were better than 2 hPBG and FBG, and 2hPBG equals FBG. Mean-

Table 2. Pros and cons of using either HbA1c or glucose-based tests for the diagnosis of diabetes mellitus

\begin{tabular}{llll}
\hline & $\mathrm{HbA}_{1 \mathrm{c}}$ measurement & \multicolumn{2}{c}{ Glucose measurements } \\
\hline Pro & Contra & Pro & Contra \\
\hline - Stable & - Influenced by many factors: & - Diabetes is a "glucose disease" & - Pre-analytical problems \\
- Time-averaged & Hematinic: 'Odd' Hb & - Time honoured & - Need to fast \\
- Reproducible & Systemic: & - Many data & \\
- Requires no fasting & Dyslipidaemia & - Allow international comparison & \\
& Pregnancy & - Analysis accurate & \\
& Malignancy & - Much cheaper & \\
& Cirrhosis & & \\
\hline
\end{tabular}


Table 3. Estimated average glucose (eAG)

\begin{tabular}{lcc}
\hline HbA1c (\%) & eAG (mg/dL) & eAG (mmoL/L) \\
\hline 5 & $97(76-120)$ & $5.4(4.2-6.7)$ \\
6 & $126(100-152)$ & $7.0(5.5-8.5)$ \\
7 & $154(123-185)$ & $8.6(6.8-10.3)$ \\
8 & $183(147-217)$ & $10.2(8.1-12.1)$ \\
9 & $212(170-249)$ & $11.8(9.4-13.9)$ \\
10 & $240(193-282)$ & $13.4(10.7-15.7)$ \\
11 & $269(217-314)$ & $14.9(12.0-17.5)$ \\
12 & $298(240-347)$ & $16.5(13.3-19.3)$ \\
\hline
\end{tabular}

Adapted from ADA [17]

while, to predict macrovascular complications, $\mathrm{HbA} 1 \mathrm{c}$ is better than 2hPBG and 2hPBG is better than FBG. In accordance with the doctor's judgment or patient preference, an $\mathrm{HbA} 1 \mathrm{c}$ target lower than $7 \%$ is acceptable, and even profitable if achieved safely without incidence of hypoglycaemia and drug side effects. The $\mathrm{HbA1c}$ goal is looser, for example $<8 \%$ is acceptable for patients with limited length of life, or the risk of treatment is greater than the beneficial effects [17]. In healthy elderly patients with little co-existing chronic disease with good cognitive function and functional status the glycaemic target could be lower (HbA1c 7-7.5\%), whereas for those with multiple co-existing chronic diseases, cognitive impairment, or functional dependence, the $\mathrm{HbA} 1 \mathrm{c}$ target would be looser, is 9.0-8.5\% [18]. For monitoring purposes, ADA (2021) recommending $\mathrm{HbA} 1 \mathrm{c}$ examination at least every 6 months (2 times a year) for DM patients who have achieved therapeutic goals (stable glycaemic control); every 3 months (4 times a year) for patients who need a change in therapy or have not achieved therapy goals; and the HbA1c test allows it to be used to make changes to treatment [17].

The most frequent question asked by doctors, especially in areas where it is difficult in terms of HbA1c examination, is whether there is a match between $\mathrm{HbA} 1 \mathrm{c}$ and blood glucose levels that can be used as a parameter for achieving therapeutic goals for DM patients. The relationship between mean blood glucose levels and $\mathrm{HbA} 1 \mathrm{c}$ based on data from the International A1C-Derived Average Glucose (ADAG) study, as quoted from ADA (2021), can be seen in Table 3 [17].

The relationship between $\mathrm{HbA} 1 \mathrm{c}$ levels and the outcome of micro-and macrovascular complications has long been known. Based on the United Kingdom Prospective Diabetes Study (UKPDS), glycaemic control (HbA1c) is a good parameter to predict the incidence of vascular complication outcome. The higher the
$\mathrm{HbA1C}$, the higher the incidence of vascular complications. Each $1 \%$ reduction in $\mathrm{HbA} 1 \mathrm{c}$ was associated with a $21 \%$ reduction in risk of all DM-related complications, $21 \%$ DM-related death, $14 \%$ for myocardial infarction, $12 \%$ for stroke, $16 \%$ for heart failure, $37 \%$ for microvascular complications, $19 \%$ for cataracts extraction, $43 \%$ for amputation or death from peripheral artery disease [19]. Other studies have shown that $\mathrm{HbA1c}$ is an important risk factor for all-cause death (number 4, after smoking, physical activity, and marital status) and number one for the risk of acute myocardial infarction in DM patients after being followed for 5.7 years [20].

The Strong Heart Study, a study in a population with a high prevalence of diabetes, examined the association of HbA1 c with CVD. Of the total 4549 American Indians included in this study (1989-1991), 3850 individuals (60\%) had FBG and HbA1c examined and had no CVD at baseline; 1386 has DM. CVD was assessed after a median of more than 15 years. The result was that elevated $\mathrm{HbA} 1 \mathrm{c}$ was associated with CVD risk especially for those with DM [21]. The impact of glycaemic control on residual cardiovascular risk in DM patients and a high risk of CVD treated with statins was reported by Menon et al. [22]. This study is part of the ACCELERATE (Assessment of Clinical Effects of Cholesteryl Ester Transfer Protein Inhibition with Evacetrapib in Patients at a High Risk for Vascular Outcomes) trial. In this study, it was found that glycaemic control $(\mathrm{HbA} 1 \mathrm{c})$ is still a strong predictor of cardiovascular outcome in those at high risk of cardiovascular disease with diabetes and having received statin therapy. In one study by Gu et al. [23] investigated the relationship between $\mathrm{HbA1c}$ variability and long-term outcome in subjects with heart failure and T2DM. Of the 902 subjects, 32.2\% had a preserved ejection fraction (HFpEF), 14.5\% mid-range ejection fraction (HFmrEF), and $53.3 \%$ reduced ejection fraction (HFrEF). High HbA1c variability (above median) was associated with all-cause mortality or a composite endpoint (death and heart failure readmission), and $\mathrm{HbA1c}$ variability was an independent predictor for all-cause mortality and the composite endpoints, regardless of ejection fraction.

Besides the mean $\mathrm{HbA} 1 \mathrm{c}$, the variability of $\mathrm{HbA} 1 \mathrm{c}$ was also associated with various outcomes related to DM. HbA1c variability can be measured by assessing the intraindividual standard deviation or coefficient of variation as well as the range of all measures (in\%). $\mathrm{HbA} 1 \mathrm{c}$ levels have a strong relationship with the incidence of macroalbuminuria in subjects with T2DM without and with microalbuminuria. A prospective study by Chiu et al. [24] in 193 T2DM patients without macroalbuminuria were followed for 6 years. Eighty-three out of 193 patients were found to have macroalbuminuria. 
Table 4. Advantages and disadvantages of the diagnosis of diabetes by fasting plasma glucose, OGTT and HbA1c

\begin{tabular}{|c|c|c|}
\hline Fasting plasma glucose & OGTT & HbA1c \\
\hline $\begin{array}{l}\text { Advantages } \\
\text { - Glucose assay easily automated } \\
\text { - Widely available } \\
\text { - Inexpensive } \\
\text { - Single sample }\end{array}$ & $\begin{array}{l}\text { Advantages } \\
\text { - Sensitive indicator of risk of } \\
\text { developing diabetes } \\
\text { - An early marker of impaired } \\
\text { glucose homeostasis }\end{array}$ & $\begin{array}{l}\text { Advantages } \\
\text { - The subject need not be fasting } \\
\text { - Samples may be obtained any time } \\
\text { of the day } \\
\text { - Very little biological variability } \\
\text { - Sample stable } \\
\text { - Not altered by acute factors, e.g., stress, } \\
\text { exercise } \\
\text { - Reflects long-term blood glucose } \\
\text { concentration } \\
\text { - Assay standardized across instruments } \\
\text { - The accuracy of the test is monitored } \\
\text { - Single sample, namely whole blood } \\
\text { - Concentration predicts the development } \\
\text { of microvascular complications of diabetes } \\
\text { - Used to guide treatment }\end{array}$ \\
\hline $\begin{array}{l}\text { Disadvantages } \\
\text { - A patient must fast }>8 \mathrm{~h} \\
\text { - Large biological variability } \\
\text { - Diurnal variation } \\
\text { - Sample not stable } \\
\text { - Numerous factors alter glucose } \\
\text { concentrations, e.g., stress, acute illness C } \\
\text { No harmonization of glucose testing } \\
\text { - The concentration varies with the source } \\
\text { of the sample (venous, capillary, or arterial } \\
\text { blood) } \\
\text { - Concentration in whole blood is different } \\
\text { from that in plasma } \\
\text { - Guidelines recommend plasma, but many } \\
\text { laboratories measure serum glucose } \\
\text { - FPG less tightly linked to diabetes } \\
\text { complications (than A1C) } \\
\text { - Reflects glucose homeostasis at a single } \\
\text { point in time }\end{array}$ & $\begin{array}{l}\text { Disadvantages } \\
\text { - Lacks reproducibility } \\
\text { - Extensive patient preparation } \\
\text { - Time-consuming and } \\
\text { inconvenient for patients } \\
\text { - Unpalatable } \\
\text { - Expensive } \\
\text { - Influenced by numerous } \\
\text { medications } \\
\text { - Subject to the same limitations } \\
\text { as FPG, namely, sample not } \\
\text { stable, need to be performed } \\
\text { in the morning, etc. }\end{array}$ & $\begin{array}{l}\text { Disadvantages } \\
\text { - May be altered by factors other than } \\
\text { glucose, e.g., change in erythrocyte life } \\
\text { span, ethnicity } \\
\text { - Some conditions interfere with the } \\
\text { measurement, e.g., selected } \\
\text { hemoglobinopathies } \\
\text { - May not be available in some laboratories/ } \\
\text { /areas of the world } \\
\text { - Cost }\end{array}$ \\
\hline
\end{tabular}

OGTT: oral glucose tolerance test. Adapted from [31]

Those with high microalbuminuria and $\mathrm{HbA} 1 \mathrm{c}$ showed the highest incidence of macroalbuminuria. It was concluded that those with higher $\mathrm{HbA} 1 \mathrm{c}$ variability were more likely to develop macroalbuminuria than those with microalbuminuria. From UK primary care data, a total of 58832 T2DM patients were studied regarding the relationship between mean and $\mathrm{HbA} 1 \mathrm{c}$ variability and mortality and admission to the emergency room, adjusted for age, sex, smoking, body mass index, and duration of DM. In this study, it was found that $\mathrm{HbA} 1 \mathrm{C}$ variability was strongly associated with overall mortality and hospitalization in the emergency room and was not associated with mean $\mathrm{HbA1c}$ and episodes of hypoglycemia [25]. In a part of EMPA-REG OUTCOME trial, Ceriello et al. [26] reported that high HbA1c variability values (within patients based on measurement of standard deviation, coefficient of variation, and $\mathrm{HbA} 1 \mathrm{c}$ ranges) were associated with an increased risk of cardiovascular death. One study in T1DM patients showed that not only long-term glycaemic control but also $\mathrm{HbA} 1 \mathrm{c}$ variability was associated with the incidence of diabetic peripheral neuropathy [27]. And a Chinese study by Lui et al. [28] found that $\mathrm{HbA} 1 \mathrm{c}$ variability was an independent positive predictor of femoral fracture in 
Table 5. Medical conditions that can lead to falsely elevated or low HbA1c levels

\begin{tabular}{ll}
\hline Conditions causing HbA1c variations & Mechanism \\
\hline Falsely high HbA1c levels & \\
\hline - Iron deficiency/pernicious anaemia & - Low erythrocyte turn-over \\
- Hemoglobinopathies (Thalassemia, HbF, HbS) & - Multifactorial: Anaemia \\
- Kidney disease & - Increased haemoglobin carbamylation, erythropoietin deficiency \\
- Jaundice & - Bilirubin causes increased glycation \\
\hline Falsely low HbA1c levels & \\
\hline - Haemolysis & - Rapid cell turnover \\
- Splenic sequestration & - Rapid cell turnover \\
- Haemodialysis in CKD & - Removal of urea leading to less carbamylation of haemoglobin \\
- Hemoglobinopathies & - Multifactorial: Haemolysis, transfusions \\
- Erythropoietin treatment & - Increased RBC production \\
- Treatment of iron deficiency/ pernicious anaemia & - Increased RBC production \\
- Blood transfusions & - Haemodilution \\
- Pregnancy & - Physiological changes \\
\hline
\end{tabular}

Adapted from [30]

T2DM patients, across a spectrum of varying degrees of glycaemic control. In a study involving 342,059 veterans with DM aged 65 years or older, followed for 3 years, found that $\mathrm{HbA} 1 \mathrm{c}$ variability and increased $\mathrm{HbA} 1 \mathrm{c}$ was associated with a greater risk of hospital admission related to hypoglycaemia in elderly DM patients [29].

\section{Limitations of HbA1c}

The accuracy and precision of the HbA1c examination have been achieved thanks to the implementation of the NGSP criteria since 2007. However, the HbA1c value may be found to be different if examined by different methods due to differences in the sensitivity of the method to various $\mathrm{Hb}$ variants. This is important to note for clinicians where in their area there are many variants of $\mathrm{Hb}$. There are several testing methods with their respective limitations: immunoassays (secondthird generation) are affected by rare variants of $\mathrm{Hb}$; enzymatic assays during analysis were not affected by $\mathrm{Hb}$ variants; capillary electrophoresis when analytic was not affected by $\mathrm{Hb}$ variant; ion-exchange chromatography is affected by all $\mathrm{Hb}$ variants including carbamylated $\mathrm{Hb}$, and boronate affinity chromatography measures total glycated $\mathrm{Hb}$ not only $\mathrm{HbA1c}$ [30].

The results of examining glucose and $\mathrm{HbA} 1 \mathrm{c}$ levels for the diagnosis of DM can be influenced by several factors. These factors can be divided into 3, namely biological, pre-analytic, and analytic factors. Biological variation consists of differences within individuals (intraindividual) and between two or more people (interindividual). Preanalytical issues regarding sample material before inspection; and differences in analytical results comes from examination procedures. The factors above cause the advantages and disadvantages of examining FBG, oral glucose tolerance test (OGTT), and $\mathrm{HbA} 1 \mathrm{C}$ as parameters for the diagnosis of DM, as shown in Table 4 [31].

As a monitoring parameter for glycaemic control, $\mathrm{HbA} 1 \mathrm{c}$ reflected mean blood glucose levels for about 3 months. Although it can be used as a target for long-term therapy, HbA1c cannot be used to see the variability of blood glucose in the short term and to see the incidence of hypoglycaemia. Whereas hyperglycaemia and hypoglycaemia due to high blood glucose variability are associated with vascular complications. An excellent example is provided by Chehregosha et al. [32] where two patients had the same HbA1c levels but had very different blood glucose variability. For 15 days of monitoring blood glucose, the two patients had the same $\mathrm{HbA} 1 \mathrm{c}$, were $8.0 \%$, but different degrees of glycaemic variability. The high glycaemic variability in Patient 1 indicates multiple episodes of hypo- and hyperglycaemia, whereas the low glycaemic variability in Patient 2 does not indicate the above episodes. Patient 1 had higher glucose fluctuation than Patient 2 causing seven episodes of moderate hypoglycaemia ( $\leq 50 \mathrm{mg} / \mathrm{dL}$ ) and eight episodes of moderate hyperglycaemia (350 mg/dL).

As a parameter for monitoring treatment goals, although the $\mathrm{HbA} 1 \mathrm{c}$ test has been standardized, several medical conditions that affect erythrocyte turn-over or a longer or shorter erythrocyte survival time can affect 
$\mathrm{HbA1}$ c levels. Besides, the conditions that cause increased carbamylation and glycation affect the value of $\mathrm{HbA1c}$. Medical conditions that can affect $\mathrm{HbA} 1 \mathrm{c}$ levels are shown in Table 5 [30]. Apart from medical conditions, some drugs also cause false high $\mathrm{HbA} 1 \mathrm{c}$ levels such as high doses of aspirin and chronic opioid use (affecting examination); and causes false low $\mathrm{HbA} 1 \mathrm{c}$ such as the use of dapsone, ribavirin, antiretroviral, trimethoprim-sulfamethoxazole (increases erythrocyte destruction), hydroxyurea (disrupts $\mathrm{Hb}$ ), vitamin C, vitamin E, small doses of aspirin (disrupts glycation) [33]. In certain circumstances other parameters can be used such as fructosamine or glycated albumin with several advantages and disadvantages over $\mathrm{HbA} 1 \mathrm{c}$ assays. The advantages are it is more reliable in certain medical conditions such as kidney disease, detects fluctuations in blood glucose earlier, identifies impaired glucose before $\mathrm{HbA} 1 \mathrm{c}$ changes, and is more cost-effective. The disadvantages are there is no standard examination, there is no standard guideline for therapeutic targets to be achieved, the prognostic strength is unclear due to limited medical evidence, more frequent examinations are needed because it predicts glycaemic control in a shorter time [30].

\section{Conflict of interest}

The author declared no conflicts of interest.

\section{REFERENCES}

1. Schechter AN. Hemoglobin research and the origins of molecular medicine. Blood. 2008; 112(10): 3927-3938, doi: 10.1182/ blood-2008-04-078188, indexed in Pubmed: 18988877.

2. Gupta S, Jain U, Chauhan N. Laboratory Diagnosis of HbA1c: A Review. J Nanomed Res. 2017; 5(4), doi: 10.15406/ jnmr.2017.05.00120.

3. Clark SLD, Santin AE, Bryant PA, et al. The initial noncovalent binding of glucose to human hemoglobin in nonenzymatic glycation. Glycobiology. 2013; 23(11): 1250-1259, doi: 10.1093/glycob/ cwt061, indexed in Pubmed: 23926230.

4. Hörber $S$, Achenbach $P$, Schleicher $E$, et al. Harmonization of immunoassays for biomarkers in diabetes mellitus. Biotechnol Adv. 2020; 39: 107359, doi: 10.1016/j.biotechadv.2019.02.015, indexed in Pubmed: 30802485.

5. Sherwani SI, Khan HA, Ekhzaimy A, et al. Significance of HbA1c Test in Diagnosis and Prognosis of Diabetic Patients. Biomark Insights. 2016; 11: 95-104, doi: 10.4137/BMI.S38440, indexed in Pubmed: 27398023.

6. Weykamp C. HbA1c: a review of analytical and clinical aspects. Ann Lab Med. 2013; 33(6): 393-400, doi: 10.3343/ alm.2013.33.6.393, indexed in Pubmed: 24205486.

7. Little RR, Rohlfing C, Sacks DB. The National Glycohemoglobin Standardization Program: Over 20 Years of Improving Hemoglobin A Measurement. Clin Chem. 2019; 65(7): 839-848, doi: 10.1373/ clinchem.2018.296962, indexed in Pubmed: 30518660.

8. Bonora E, Kiechl S, Mayr A, et al. High-normal HbA1c is a strong predictor of type 2 diabetes in the general population. Diabetes Care. 2011; 34(4): 1038-1040, doi: 10.2337/dc10-1180, indexed in Pubmed: 21307378.

9. Zhang $X$, Gregg EW, Williamson DF, et al. A1C level and future risk of diabetes: a systematic review. Diabetes Care. 2010; 33(7):
1665-1673, doi: 10.2337/dc09-1939, indexed in Pubmed: 20587727.

10. Jang JY, Moon S, Cho S, et al. Visit-to-visit HbA1c and glucose variability and the risks of macrovascular and microvascular events in the general population. Sci Rep. 2019; 9(1): 1374, doi: 10.1038/s41598-018-37834-7, indexed in Pubmed: 30718626.

11. Cavero-Redondo I, Peleteiro B, Álvarez-Bueno C, et al. Glycated haemoglobin $\mathrm{A} 1 \mathrm{c}$ as a risk factor of cardiovascular outcomes and all-cause mortality in diabetic and non-diabetic populations: a systematic review and meta-analysis. BMJ Open. 2017; 7(7): e015949, doi: 10.1136/bmjopen-2017-015949, indexed in Pubmed: 28760792.

12. Mitsios JP, Ekinci El, Mitsios GP, et al. Relationship Between Glycated Hemoglobin and Stroke Risk: A Systematic Review and Meta-Analysis. J Am Heart Assoc. 2018; 7(11), doi: 10.1161/ JAHA.117.007858, indexed in Pubmed: 29773578.

13. Ghouse J, Skov MW, Kanters JK, et al. Visit-to-Visit Variability of Hemoglobin A in People Without Diabetes and Risk of Major Adverse Cardiovascular Events and All-Cause Mortality. Diabetes Care. 2019; 42(1): 134-141, doi: 10.2337/dc18-1396, indexed in Pubmed: 30352898.

14. Perkumpulan Endokrinologi Indonesia (Perkeni). Pedoman Pengelolaan dan Penegahan Diabetes Melitus. Tipe 2 Dewasa di Indonesia 2019. Penerbit PB Perkeni. Jakarta, 2019.

15. American Diabetes Association. 2. Classification and Diagnosis of Diabetes: . Diabetes Care. 2021; 44(Suppl 1): S15-S33, doi: 10.2337/dc21-S002, indexed in Pubmed: 33298413.

16. Davies $P$, Chellamuthu $P$, Patel V. How to Diagnose Diabetes? Practicalities and Comments on the WHO Provisional Recommendation in Favour of HbA1c. Brit J Diabetes Vasc Dis. 2010; 10(6): 261-264, doi: 10.1177/1474651410394258.

17. American Diabetes Association (ADA). Glycemic Targets: Standards of Medical Care in Diabetes-2021. Diabetes Care. 2020; 44(Suppl 1): S73-S84, doi: 10.2337/dc21-s006.

18. American Diabetes Association (ADA). Older Adults: Standards of Medical Care in Diabetes-2021. Diabetes Care. 2020; 44(Supplement 1): S168-S179, doi: 10.2337/dc21-s012.

19. Stratton IM, Adler Al, Neil HA, et al. Association of glycaemia with macrovascular and microvascular complications of type 2 diabetes (UKPDS 35): prospective observational study. BMJ. 2000; 321(7258): 405-412, doi: 10.1136/bmj.321.7258.405, indexed in Pubmed: 10938048.

20. Rawshani A, Rawshani A, Franzén S, et al. Risk Factors, Mortality, and Cardiovascular Outcomes in Patients with Type 2 Diabetes. N Engl J Med. 2018; 379(7): 633-644, doi: 10.1056/ NEJMoa1800256, indexed in Pubmed: 30110583.

21. Wang $H$, Shara NM, Lee ET, et al. Hemoglobin A1c, fasting glucose, and cardiovascular risk in a population with high prevalence of diabetes: the strong heart study. Diabetes Care. 2011; 34(9): 1952-1958, doi: 10.2337/dc11-0329, indexed in Pubmed: 21788631.

22. Menon V, Kumar A, Patel DR, et al. Impact of Baseline Glycemic Control on Residual Cardiovascular Risk in Patients With Diabetes Mellitus and High-Risk Vascular Disease Treated With Statin Therapy. J Am Heart Assoc. 2020; 9(1): e014328, doi: 10.1161/ JAHA.119.014328, indexed in Pubmed: 31852422.

23. Gu J, Pan JA, Fan YQ, et al. Prognostic impact of HbA1c variability on long-term outcomes in patients with heart failure and type 2 diabetes mellitus. Cardiovasc Diabetol. 2018; 17(1): 96, doi: 10.1186/s12933-018-0739-3, indexed in Pubmed: 29960591.

24. Chiu WC, Lai YR, Cheng BC, et al. HbA1C Variability Is Strongly Associated with Development of Macroalbuminuria in Normal or Microalbuminuria in Patients with Type 2 Diabetes Mellitus: A Six-Year Follow-Up Study. Biomed Res Int. 2020; 2020: 7462158, doi: 10.1155/2020/7462158, indexed in Pubmed: 32047814.

25. Critchley JA, Carey IM, Harris T, et al. Variability in Glycated Hemoglobin and Risk of Poor Outcomes Among People With Type 2 Diabetes in a Large Primary Care Cohort Study. Diabetes Care. 
2019; 42(12): 2237-2246, doi: 10.2337/dc19-0848, indexed in Pubmed: 31582426.

26. Ceriello A, Ofstad AP, Zwiener I, et al. Empagliflozin reduced longterm $\mathrm{HbA} 1 \mathrm{c}$ variability and cardiovascular death: insights from the EMPA-REG OUTCOME trial. Cardiovasc Diabetol. 2020; 19(1): 176, doi: 10.1186/s12933-020-01147-9, indexed in Pubmed: 33050931.

27. Pinto MV, Rosa LC, Pinto LF, et al. HbA1c variability and long-term glycemic control are linked to peripheral neuropathy in patients with type 1 diabetes. Diabetol Metab Syndr. 2020; 12: 85, doi: 10.1186/s13098-020-00594-4, indexed in Pubmed: 33042229.

28. Lui DTW, Lee $\mathrm{CH}$, Chan $\mathrm{YH}$, et al. HbA1c variability, in addition to mean $\mathrm{HbA1c}$, predicts incident hip fractures in Chinese people with type 2 diabetes. Osteoporos Int. 2020; 31(10): 1955-1964, doi: 10.1007/s00198-020-05395-z, indexed in Pubmed: 32385660 .

29. Zhao MJY, Prentice JC, Mohr DC, et al. Association between hemoglobin A1c variability and hypoglycemia-related hospitaliza- tions in veterans with diabetes mellitus. BMJ Open Diabetes Res Care. 2021; 9(1), doi: 10.1136/bmjdrc-2020-001797, indexed in Pubmed: 33431600.

30. Fayyaz B, Rehman HJ, Minn H. Interpretation of hemoglobin A1C in primary care setting. J Community Hosp Intern Med Perspect. 2019; 9(1): 18-21, doi: 10.1080/20009666.2018.1559432, indexed in Pubmed: 30788069.

31. Sacks DB. A1C versus glucose testing: a comparison. Diabetes Care. 2011; 34(2): 518-523, doi: 10.2337/dc10-1546, indexed in Pubmed: 21270207.

32. Chehregosha H, Khamseh ME, Malek M, et al. A View Beyond HbA1c: Role of Continuous Glucose Monitoring. Diabetes Ther. 2019; 10(3): 853-863, doi: 10.1007/s13300-019-0619-1, indexed in Pubmed: 31037553.

33. Unnikrishnan R, Anjana RM, Mohan V. Drugs affecting HbA1c levels. Indian J Endocr Metab. 2012; 16(4): 528, doi: 10.4103/22308210.98004 . 